Original Research Paper

\title{
Determining the Time Required to Detect Induced Sow Lameness Using an Embedded Microcomputer-Based Force Plate System
}

\author{
${ }^{1}$ Brady McNeil, ${ }^{2,3}$ Julia Calderón Díaz, ${ }^{1}$ Caitlyn Bruns, ${ }^{1}$ Joe Stock, \\ ${ }^{4}$ Suzanne Millman, ${ }^{1}$ Anna Johnson, ${ }^{4}$ Locke Karriker and ${ }^{1}$ Kenneth Stalder \\ ${ }^{I}$ Department of Animal Science, Iowa State University, Ames, Iowa 50011, USA \\ ${ }^{2}$ Teapasc Moorepark Grassland Research and Innovation Centre, Pig Development, Fermoy, Co. Cork, Ireland \\ ${ }^{3}$ Polish Academy of Sciences, Institute of Genetics and Animal Breeding, \\ Department of Animal Behaviour and Welfare, Jastrzebiec, Magdalenka, Poland \\ ${ }^{4}$ Veterinary Diagnostic and Production Animal Medicine, Iowa State University, Ames, Iowa 50011, USA
}

Article history

Received: 08-01-2018

Revised: 03-04-2018

Accepted: 02-05-2018

Corresponding Author: Brady McNeil

Department of Animal Science, Iowa State University, Ames, Iowa 50011, USA

Tel: $+1-402-910-4702$

Fax: $+1-402-563-9658$

Email: bmcneil@dnaswinegenetics.com

\section{Introduction}

Sow longevity is a key factor in commercial swine herd profitability (Stalder et al., 2004). Currently, in the USA, annual sow culling and mortality rates are $43.46 \%$ and $8.81 \%$, respectively (PigCHAMP, 2014). After reproductive problems, lameness is the most common reason for premature sow culling from breeding herds

\begin{abstract}
Lameness in swine breeding herds is a common cause of compromised animal well-being and economic loss to pig producers. Current lameness assessment methods are subjective and require intensive training. It has been shown that embedded microcomputer-based force plate systems can detect lameness by measuring weight distributions in livestock. The objective of this study was to determine the minimum time required to record data from each individual load cell in the force plate system to obtain accurate sow weight distributions on each leg. Sound and induced lameness states were evaluated to ensure that time requirements were similar for both situations. Lameness was induced in 12 mixed parity sows on Day 0 using a chemical synovitis model. An embedded microcomputerbased force plate system measured weight bearing applied on each foot twice per second for $15 \mathrm{~min}$ on days $-1,+1,+6$ and +10 relative to lameness induction. Data were analyzed using mixed model equations with day relative to lameness induction, time period, foot and the injected foot included as fixed effects and sow within replicate included as a random effect. Results indicate sow weight distributions at 1 and 5 cumulative minutes were not different $(\mathrm{p} \geq 0.05)$ when compared to those cumulative results recorded for $10 \mathrm{~min}$. Comparing weights for each minute across time identified potential data collection problems after 12 $\mathrm{min}$; therefore, $10 \mathrm{~min}$ was considered the maximum time required for weight recordings. Results from the present study indicate that recorded data for 1 min could be used as the minimum time required to accurately assess lameness for each individual animal. Results from this study can be used to improve the embedded microcomputer-based force plate use efficiency when evaluating sow lameness.
\end{abstract}

Keywords: Lameness, Force Plate, Sow, Weight Distribution 
2000; Anil et al., 2009). Therefore, lame sows may not reach a positive net present value before they are culled. It has been estimated that to recover the replacement gilt investment, a sow should remain in the breeding herd for at least 3 parities (Stalder et al., 2003). To minimize involuntary sow culling due to lameness, evaluation methods that are accurate, objective and quick are required.

The embedded microcomputer-based force plate system developed by Sun et al. (2011), hereafter referred to as force plate, was designed for placement under an electronic single space feeder or a gestation stall. Previous research demonstrated the force plate's capacity to detect induced sow lameness by measuring separately the weight she is willing to bear on each leg during 5, 15 and $30 \mathrm{~min}$ tests (Sun et al., 2011; Karriker et al., 2013; Pluym et al., 2013; Abell et al., 2014; Mohling et al., 2014). The average occupation time required for a sow to consume her daily feed allotment is 9.2 to $14.2 \mathrm{~min}$, however, this may be across multiple feedings (Olsson et al., 2011). Hence, test duration for individual sows as they go through an electronic sow feeding system is a critical feature for practical application in a commercial setting. Therefore, the objective of this study was to determine the minimum time required to record data from each individual load cell in the force plate for reliable and accurate sow weight distribution and lameness detection.

\section{Materials and Methods}

Experimental protocols for this study were reviewed and approved by the Iowa State University Institutional Animal Care and Use Committee. Twelve multiparous commercial sows with no observable clinical lameness signs and an average weight of $210.1 \pm 35.5 \mathrm{~kg}$ were used. A lameness induction model, previously validated for swine (Karriker et al., 2013) was used for producing repeatable transient lameness. Sows were injected with 10 $\mathrm{mg} \mathrm{mL}^{-1}$ amphotericin B (X-Gen Pharmaceuticals, Inc.) in their distal interphalangeal joint on day 0 to induce lameness in 1 of 2 randomized injections sites: Right Rear foot (RR) or Left Rear foot (LR). After each sow had returned to a sound condition (i.e., non-lame state 13 days post injection), the injection process was repeated on all sows, for a total of 3 replicates. For further details about the lameness induction protocol see Karriker et al. (2013).

Weight bearing measurements for each foot were collected using a force plate (Sun et al., 2011). Force plate dimensions were $1.5 \times 0.57 \times 0.11 \mathrm{~m}$ (length $\times$ width $\times$ height) with $6.4 \mathrm{~mm}$ thick aluminum plating comprising the bottom plate and 4 top plates. Sows were encouraged to walk into a gestation stall with the force plate as the flooring on days $-1,+1,+6$ and +10 relative to lameness induction. Approximately $50 \mathrm{~g}$ of feed was placed in a feeding trough at the front of the stall before the sow entered and additional feed was provided by slowly hand trickle feeding as the sows consumed the feed up to $2.72 \mathrm{~kg}$. Weight bearing on each foot was recorded twice per second for 15 minutes on 4 collection days per replicate. Once the information was collected, data were edited. Records were excluded from the data set based on the following criteria: (1) if the total weight of the sow (Left Front [LF] + Right Front $[R F]+$ Left Rear [LR] + Right Rear [RR]) was less than 90.7 kg; (2) if individually both front legs or both rear legs of the sow weighed less than $4.5 \mathrm{~kg}$; or (3) if any foot individually weighed less than $0 \mathrm{~kg}$. These criteria were previously used by Abell et al. (2014) to indicate that the sow's feet were not properly positioned on each quadrant of the force plate. When the feet are not positioned correctly, the measurements recorded are not an accurate representation of the sow's weight distribution.

The percentage of the total force applied by each sow, on each quadrant, per injected foot, for each day was calculated (i.e., Individual Hoof/Total Sow Weight). Descriptive statistics were obtained using SAS v9.3 PROC MEANS (SAS, Cary, NC). Descriptive statistics included: average force (mean), standard deviation of the force applied, skewness (i.e., measurement to evaluate the degree of asymmetry for the distribution of the force applied for each quadrant), 5th percentile (P5) of the force applied on each quadrant, 95th percentile (P95) and range between P95-P5 for each sow, on each quadrant, per injected foot, per day.

The P5 was used because it provides a more robust value for the minimum force the sow is willing to apply, since values of $0 \mathrm{~kg}$ were recorded when she adjusted her weight between limbs. The P95 provides a more robust value for the maximum force applied by the sow, since extreme values occurred when the sow pushed up on the feed trough or adjusted her weight. These values were also used by Abell et al. (2014) to develop a lameness classification tree from sows' force distributions.

Statistics used to evaluate these data were based on Least Squares (LS) means obtained using mixed model equation methods in SAS v9.3 PROC MIXED (SAS Inst. Inc., Cary, NC). The following mixed linear model was used:

$$
Y=D+T+F+I+R(S)+e
$$

Where:

$$
\begin{array}{ll}
Y & =\text { Force applied by sow on the force plate } \\
D & =\text { Day relative to lameness induction } \\
T & =\text { Time period } \\
F & =\text { Foot of measurement } \\
I & =\text { The foot of injection } \\
R(S) & =\text { Sow within replicate number } \\
e & =\text { error }
\end{array}
$$

Day relative to lameness induction, time period, foot and the injected foot were fitted as fixed effects and sow 
within replicate was fitted as a random effect. The same model was used for all variables analyzed.

\section{Minute Model}

A minute model was developed to more accurately identify time's impact on weight distributions. The minute model compared each minute independently (i.e., minute $1=0$ to $59 \mathrm{sec} ; \min 2=60$ to $119 \mathrm{sec})$. The statistics used to evaluate the minute traits were the same as described for the cumulative model analysis described below.

\section{Test Minute Model}

A test minute model was developed using the mean of each minute's means to identify potential data collection problems. Each minute mean (i.e., one mean for minute $1=0$ to $59 \mathrm{sec}$; $\min 2=60$ to $119 \mathrm{sec}$ ) was averaged for a total mean and standard deviation. Minute means that were greater than 2 standard deviations from the total mean were calculated. The mean weight and standard deviation for day $1 \mathrm{RR}$ with LR foot injected was the mean and standard deviation of the calculation (mean weights of $1+2+3 \ldots+15 \mathrm{~min}) / 15$. Day +1 was used, as it was the day with the most variability of data across time from sows shifting their weight to get comfortable because of the induced lame hoof.

\section{Cumulative Model}

The cumulative model included the time up to and including that increment (i.e., $1 \mathrm{~min}$ is $0 \mathrm{sec}$ [starting after all feet were on the force plate] to $60 \mathrm{sec}$ and $5 \mathrm{~min}$ is $0 \mathrm{sec}$ to $300 \mathrm{sec}$ ). Each time period was compared using mean, SEM, P5, P95, range and skewness of the sow's weight distribution at a 0.05 alpha significance level with a Bonferroni adjustment.

\section{Test Cumulative Model}

Test cumulative models using LS means were developed to identify a potential burn-in (acclimation) period or a time period at the beginning of data collection that was necessary to delete in order to account for the sows shifting weight while becoming acclimated to the force plate. A $15 \mathrm{sec}$ test model deleted the first $15 \mathrm{sec}$ and compared mean, standard deviation, P5, P95, P95-P5 and skewness, for 15 to $135 \mathrm{sec}, 15$ to $195 \mathrm{sec}, 15$ to $255 \mathrm{sec}$ and 15 to $315 \mathrm{sec}$ to 15 to $615 \mathrm{sec}$. The same statistics that were used for the $15 \mathrm{sec}$ test model were used for a $30 \mathrm{sec}$ test model where the first $30 \mathrm{sec}$ were deleted, comparing 30 to $150 \mathrm{sec}, 30$ to 210 $\mathrm{sec}, 30$ to $270 \mathrm{sec}$ and 30 to $330 \mathrm{sec}$ to 30 to $630 \mathrm{sec}$. The same statistics and level of significance that were used for the $15 \mathrm{sec}$ and $30 \mathrm{sec}$ test models were used for the $45 \mathrm{sec}$ test model where the first $45 \mathrm{sec}$ were deleted, comparing 45 to $165 \mathrm{sec}, 45$ to $225 \mathrm{sec}, 45$ to $285 \mathrm{sec}$ and 45 to $345 \mathrm{sec}$ to 45 to $645 \mathrm{sec}$.

\section{Results}

\section{Minute Model}

The mean weight bearing on each foot for each minute was compared across time for the entire $15 \mathrm{~min}$ time period when data recording occurred. Figure 1 shows the mean weight distribution across time for nonlame sows at day -1 . Figure's 2, 3 and 4 shows the mean weight distribution for the same sows that have been injected with amphotericin B in their Right Rear foot (RR) at day $+1,+6$ and +10 respectively from injection. Error bars represent significant differences $(p<0.05)$ across time for the same foot.

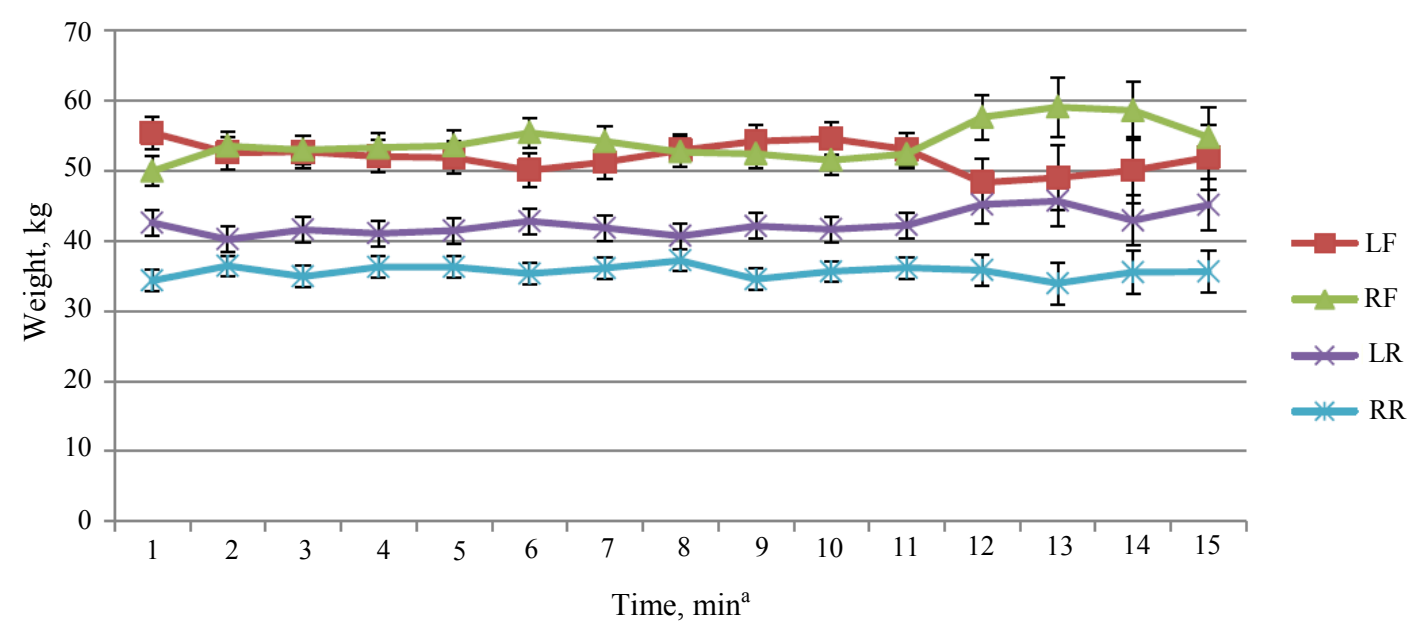

Fig. 1: Mean pressure applied to each foot per minute on Day -1 using an embedded microcomputer-based force plate ${ }^{b}$ when the rear right foot was injected on Day 0 with $10 \mathrm{mg} \mathrm{mL}^{-1}$ amphotericin $\mathrm{B}$ in their distal interphalangeal joint, using the Minute Model $^{\mathrm{c}}$; ${ }^{\mathrm{a}}$ Each minute is independent, $1 \mathrm{~min}=0$ to $59 \mathrm{sec} ; 2 \mathrm{~min}=60$ to $119 \mathrm{sec}$; ${ }^{\mathrm{b}}$ The mixed linear model used included: Day relative to lameness induction, time period and the interaction fitted as fixed effects and sow within replicate fitted as a random effect; ${ }^{c}$ Error bars show significant differences at $\mathrm{p}<0.05$ level, for mean weights across time for the same foot 


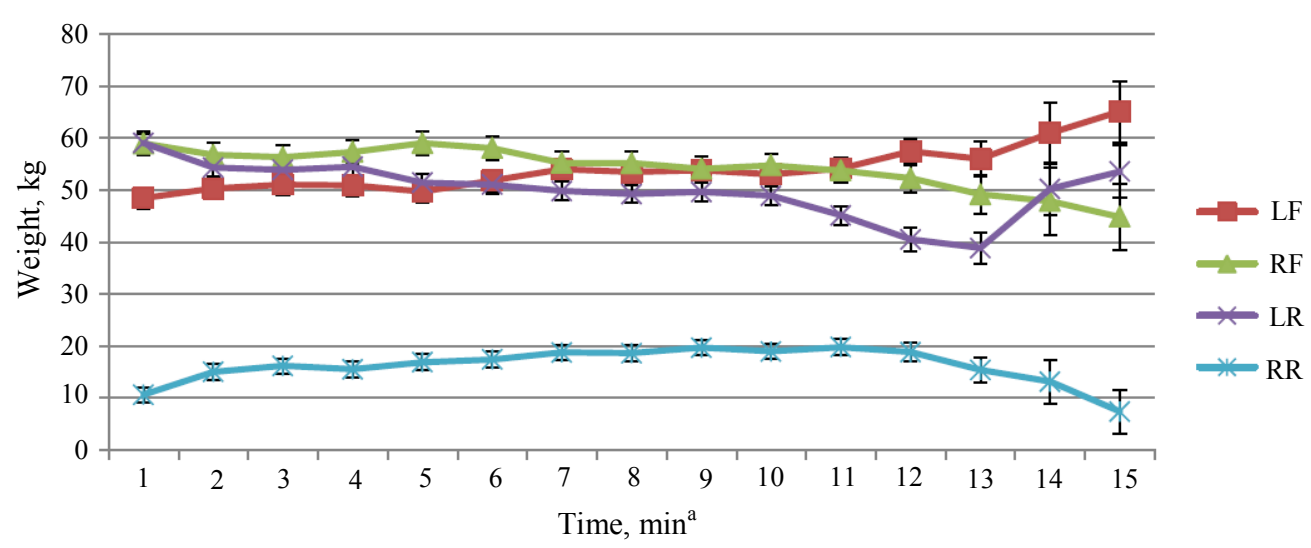

Fig. 2: Pressure applied to each foot per minute on Day +1 using an embedded microcomputer-based force plate ${ }^{\mathrm{b}}$ when the rear right foot was injected with $10 \mathrm{mg} \mathrm{mL}^{-1}$ amphotericin B in their distal interphalangeal joint using the Minute Model ${ }^{c}$; ${ }^{a}$ Each minute is independent, $1 \mathrm{~min}=0$ to $59 \mathrm{sec} ; 2 \mathrm{~min}=60$ to $119 \mathrm{sec}$; ${ }^{\mathrm{b}}$ The mixed linear model used included: Day relative to lameness induction, time period and the interaction fitted as fixed effects and sow within replicate fitted as a random effect; ${ }^{\circ}$ Error bars show significant differences at $\mathrm{p}<0.05$ level, for mean weights across time for the same foot.

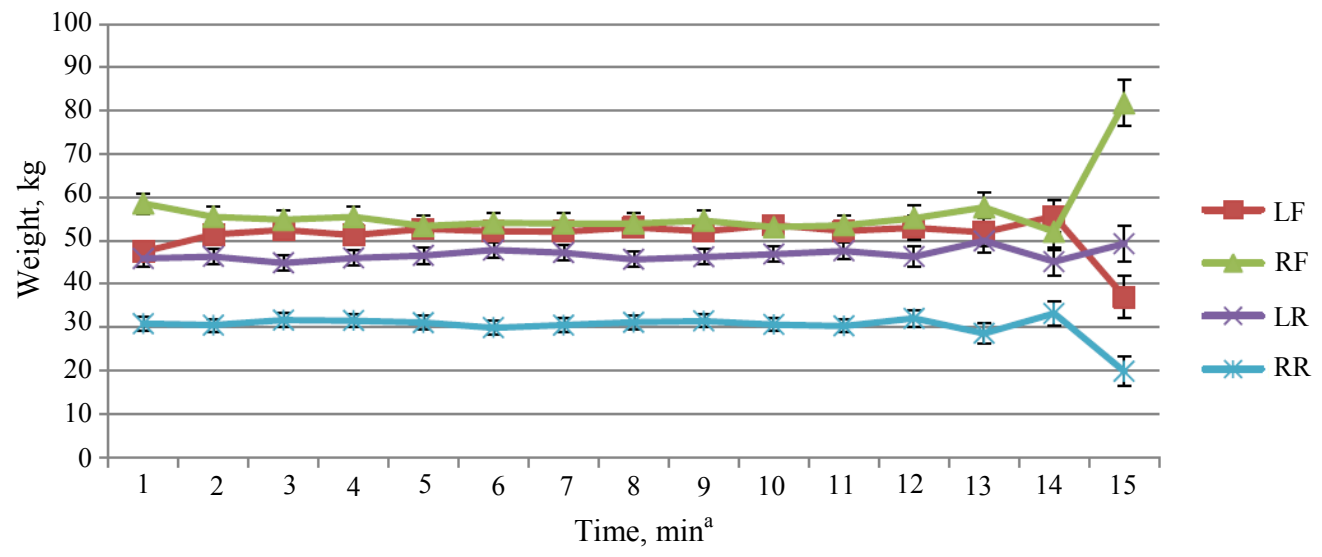

Fig. 3: Pressure applied to each foot per minute on Day +6 using an embedded microcomputer-based force plate ${ }^{\mathrm{b}}$ when the rear right foot was injected with $10 \mathrm{mg} \mathrm{mL}{ }^{-1}$ amphotericin B in their distal interphalangeal joint using the Minute Model $^{\mathrm{c}}$; ${ }^{\mathrm{a}}$ Each minute is independent, $1 \mathrm{~min}=0$ to $59 \mathrm{sec} ; 2 \mathrm{~min}=60$ to $119 \mathrm{sec}$; ${ }^{\mathrm{b}}$ The mixed linear model used included: Day relative to lameness induction, time period and the interaction fitted as fixed effects and sow within replicate fitted as a random effect; ${ }^{\mathrm{c}}$ Error bars show significant differences at $\mathrm{p}<0.05$ level, for mean weights across time for the same foot.

\section{Test Minute Model}

Minute means across all days and injection sites were compared using $2 \mathrm{SD}$ from the total average of the minute means. Observations that were greater than $2 \mathrm{SD}$ from the total average of the means were considered outliers. Minutes outside of this range 2 or more times were $2,12,13,14$ and $15 \mathrm{~min}$. It appears that after 12 min the data became more variable when compared to the 11 minutes leading up to this time. Hence, $10 \mathrm{~min}$ was selected as the time to compare weights across time.

\section{Cumulative Model}

Comparing 1, 5 and $10 \mathrm{~min}$ for each of the variables, time did not have a significant effect. Table 1 and Table 2 shows the average force applied to the right rear on the day before lameness induction (Table 1) and the day after lameness induction (Table 2).

\section{Test Cumulative Model}

The burn-ins tested were deleting the first 15, 30, or $45 \mathrm{sec}$ of the recording and then adjusting the time measured to ensure that all readings were comparing the same minute intervals of 2, 3, 4 and 5 to $10 \mathrm{~min}$. Mean, SEM, P5, P95, range and skewness for the weight distribution were compared for all feet and injection types resulting in 192 different comparisons across time. However, no differences were observed for the required time to accurately record $\mathrm{BW}$ distributions when using either of the burn-in periods $(p>0.05)$. Since no differences were seen no data are presented in this study. 


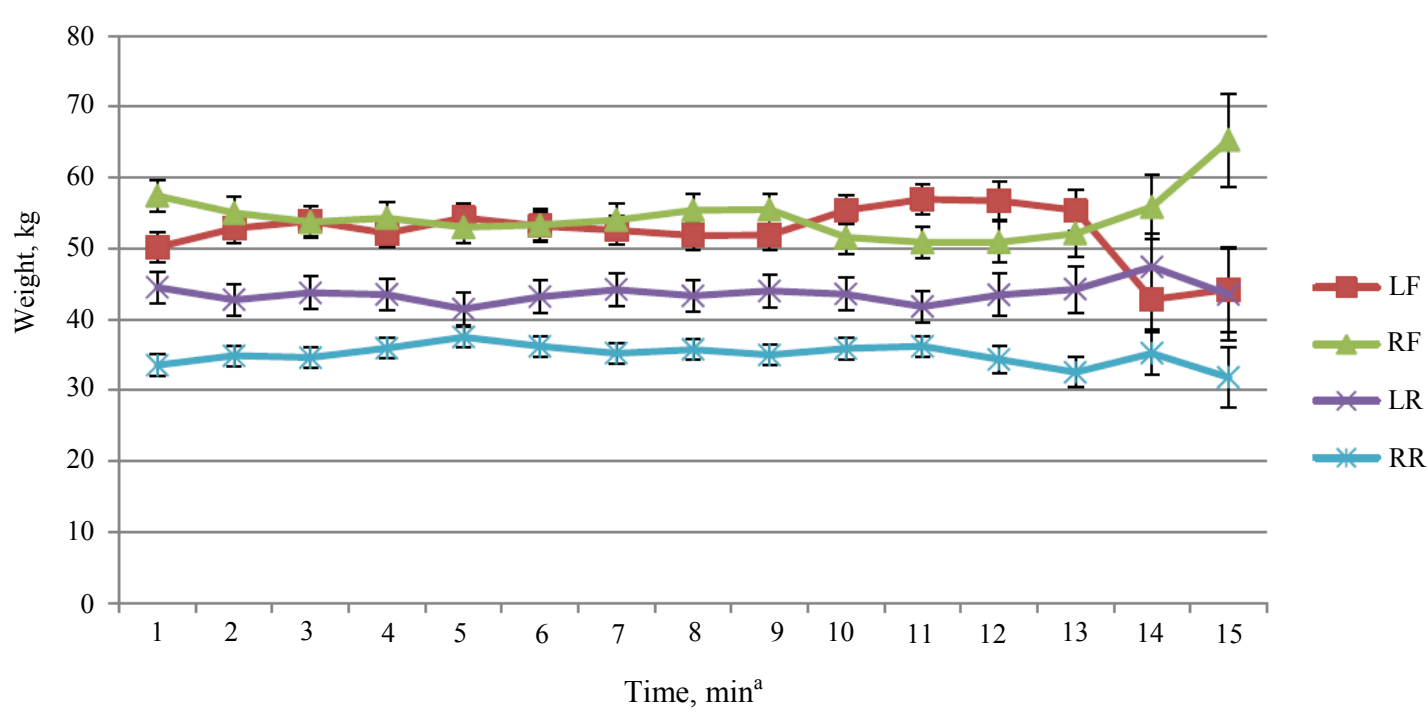

Fig. 4: Pressure applied to each foot per minute on Day +10 using an embedded microcomputer-based force plate ${ }^{\mathrm{b}}$ when the rear right foot was injected with $10 \mathrm{mg} \mathrm{mL}^{-1}$ amphotericin $\mathrm{B}$ in their distal interphalangeal joint using the Minute Model ${ }^{\mathrm{c}}$; ${ }^{\mathrm{a}}$ Each minute is independent, $1 \mathrm{~min}=0$ to $59 \mathrm{sec} ; 2 \mathrm{~min}=60$ to $119 \mathrm{sec}$; ${ }^{\text {b }}$ The mixed linear model used included: Day relative to lameness induction, time period and the interaction fitted as fixed effects and sow within replicate fitted as a random effect; ${ }^{c}$ Error bars show significant differences at $\mathrm{p}<0.05$ level, for mean weights across time for the same foot.

Table 1: Average (LS means) force applied per foot on the day before lameness induction in RR Foot ${ }^{\mathrm{a}}$

\begin{tabular}{llll}
\hline Foot & $1 \mathrm{~min}^{\mathrm{b}}$ & $5 \mathrm{~min}$ & $10 \mathrm{~min}$ \\
\hline $\mathrm{LF}^{\mathrm{c}}$ & 55.87 & 53.34 & 53.19 \\
RF & 50.25 & 53.02 & 53.29 \\
LR & 41.88 & 40.67 & 40.93 \\
RR & 35.23 & 36.54 & 36.58 \\
\hline
\end{tabular}

${ }^{\mathrm{a}}$ Force applied per foot measured in kg; ${ }^{\mathrm{b}}$ Times increments are cumulative up to that time period; ${ }^{\mathrm{c}} \mathrm{LF}=\mathrm{Left}$ Front, RF $=$ Right Front, LR $=$ Left Rear, RR=Right Rear; *** Significant differences $(\mathrm{p} \leq 0.05)$, for rows, between time intervals.

Table 2: Average (LS means) force applied (kg) per foot on the day after lameness induction in the RR Foot ${ }^{\mathrm{a}}$

\begin{tabular}{llll}
\hline Foot & $1 \mathrm{~min}^{\mathrm{b}}$ & $5 \mathrm{~min}$ & $10 \mathrm{~min}$ \\
\hline LF $^{\mathrm{c}}$ & 48.83 & 50.47 & 52.01 \\
RF & 59.31 & 58.10 & 56.98 \\
LR & 58.41 & 53.99 & 51.47 \\
RR & 11.51 & 15.67 & 17.66 \\
\hline
\end{tabular}

${ }^{\mathrm{a}}$ Force applied per foot measured in $\mathrm{kg} ;{ }^{\mathrm{b}}$ Times increments are cumulative up to that time period; ${ }^{\mathrm{c}} \mathrm{LF}=\mathrm{Left}$ Front, RF $=$ Right Front, LR = Left Rear, RR = Right Rear; *** Significant differences $(\mathrm{p} \leq 0.05)$, for rows, between time intervals.

\section{Discussion}

Lameness, if not assessed quickly and accurately, could result in a welfare issue for the sow and present a challenge to herd productivity and overall longevity. Current lameness detection methods used by the commercial industry utilize subjective scoring systems. However, these scoring systems require skilled employees and appropriate continued training, which can be challenging in an industry that has difficulty recruiting and retaining qualified and trained personnel (Loula, 2000; Main et al., 2000). In addition, there can be inter- and intra-observer variation, reducing scoring reliability (Flower and Weary, 2006; D'Eath, 2012).
Scoring reliability could be affected because of the animal's instinct to hide lameness from a visual observation, until lameness becomes severe, or from the pigs' short neck and quick stiff movements (Main et al., 2000; O'Callaghan et al., 2003). Producers who look at their animals every day may under identify the number of lame sows and thus only identify severely lame animals (Alawneh et al., 2012). Conversely, an objective measure would eliminate the inter- and intra-observer variation. Currently, research on automated and objective swine lameness detection has focused on movement with gait or footprint analysis, kinematics and accelerometers (Thorup et al., 2007; von Wachenfelt et al., 2009; Grégoire et al., 2013; Mohling et al., 2014), pressure and 
heat sensitivity (Paris-Garcia et al., 2014), stance angles (Stock et al., 2017) and force plates (Sun et al., 2011; Pluym et al., 2013).

There is limited research into the commercial viability of force plates. A key factor is the time required for an accurate measurement in sound and lame animals. Sound sows exhibited differences between rear feet (Fig. 1) with the right rear having the least force applied. In order to make sure sows had feed, a technician would stand at the sow's front right shoulder, potentially causing the sow to not apply as much weight to the rear right foot. In this study, similar to results by Sun et al. (2011) and Pluym et al. (2013) animals classified as lame show a trend for differences in mean weight bearing on each foot. Additionally, lame animals place more weight on the lame foot the longer they are on the force plate, up until 12 min as shown by the non-overlapping error bars in Fig. 2. Numerous hypotheses may have resulted in the variation after $12 \mathrm{~min}$, for example it is possible that when sows ran out of feed, they became uninterested in the system, or that sows were ready to move out of the force plate, or that some other activity may have resulted in more frequent posture changes. This suggests that $15 \mathrm{~min}$ is not the correct cumulative time to be comparing minimum time to record data while the sows are standing on the force plate.

Based on the cumulative model results, measurements of at least $1 \mathrm{~min}$ with no burn-in period could be recommended for future research into lameness identification, as Table 1 and 2 show no significant differences between 1,5 and 10 cumulative minutes. Additionally, this time meets the feeding time requirements of a sow in an ESF (Olsson et al., 2011).

When compared to current subjective lameness evaluation and detection models that require training and the time for employees to visually observe sows, the force-plate system provides opportunity to evaluate lameness in an efficient manner. The force plate system does not rely on subjective evaluation and therefore, objectively evaluates lameness. It is a repeatable, objective device that can replace or be used in conjunction with current lameness detection practices. The results from this study are based on the animals presented and further research is required to identify the parameters needed to accurately assess naturally occurring lameness in sows using the force plate, as well as to implement the device on a commercial setting.

\section{Conclusion}

Results of this study are specific to the controlled conditions described; they indicate weight bearing data collection does not require a burn-in period for the sow to adjust to the force plate. It appears that weight bearing data collected after 12 min standing on the force plate is variable due to postural changes. After comparing LS means for mean, SEM, P5, P95, range and skew for minute weights across time, 1 min provides an acceptable level of similarity to $10 \mathrm{~min}$ and could be used as the minimum amount of time needed for weight bearings to be recorded in a commercial setting.

\section{Acknowledgement}

Authors are grateful for the assistance provided by Becky Parsons, Lori Layman and the employees of the Sow Longevity Lab.

\section{Funding Information}

A portion of this project was supported by the National Pork Checkoff, National Pork Board, Des Moines, IA, (09-073); Iowa Pork Producers Association, Des Moines, IA; and the Iowa Livestock Health Advisory Council (ILHAC), Des Moines, IA.

\section{Authors Contributions}

Brady McNeil: Analyze and interpret the data and write the manuscript.

Julia Calderón Díaz, Caitlyn Bruns and Joe Stock: Analyze and interpret the data and revise the manuscript.

Suzanne Millman, Anna Johnson and Locke Karriker: Conceive and design the study, execute the study, data acquisition and revise the manuscript.

Kenneth Stalder: Conceive and design the study, analysis and interpret the data and revise the manuscript.

\section{Ethics}

Experimental protocols for this study were reviewed and approved by the Iowa State University Institutional Animal Care and Use Committee.

\section{References}

Abell, C.E., A.K. Johnson, L.A. Karriker, M.F. Rothschild and S.J. Hoff et al., 2014. Using classification trees to detect induced sow lameness with a transient model. Animal, 8: 1000-1009. DOI: $10.1017 / \mathrm{S} 1751731114000871$

Alawneh, J.I., R.A. Laven and M.A. Stevenson, 2012. Interval between detection of lameness by locomotion scoring and treatment for lameness: A survival analysis. Vet. J., 193: 622-625. DOI: $10.1016 / j . t v j 1.2012 .06 .042$

Anil, S., L. Anil and J. Deen, 2009. Effect of lameness on sow longevity. J. Am. Vet. Med. Assoc., 235: 734-738. DOI: 10.2460/javma.235.6.734

D'Allaire, S., T.E. Stein and A.D. Leman, 1987. Culling patterns in selected Minnesota swine breeding herds. Can. J. Vet. Res., 51: 506-512. PMID: 3453273 
D'Eath, R., 2012. Repeated locomotion scoring of a sow herd to measure lameness: Consistency over time, the effect of sow characteristics and inter-observer reliability. Anim. Welfare, 21: 219-231.

DOI: $10.7120 / 09627286.21 .2 .219$

Dargon, J. and A. Aumaître, 1979. Sow culling: Reasons for and effect in productivity. Livest. Prod. Sci., 6: 167-177. DOI: 10.1016/0301-6226(79)90018-6

Deen, J., S.S. Anil and L. Anil, 2007. Claw lesions as a predictor of lameness in breeding sows. Proceedings of the 58th Annual Meeting of the European Association of Animal Production, (AAP' 07), Dublin, Ireland, pp: 274-274.

Engblom, L., N. Lundeheim, A.M. Dalin and K. Andersson, 2007. Sow removal in Swedish commercial herds. Livest. Sci., 106: 76-86.

DOI: 10.1016/j.livsci.2006.07.002

Flower, F.C. and D.M. Weary, 2006. Effect of hoof pathologies on subjective assessments of dairy cow gait. J. Dairy Sci., 89: 139-146.

DOI: $10.3168 /$ jds.S0022-0302(06)72077-X

Grégoire, J., R. Bergeron, S. D’Allaire, M.S. MeunierSalaün and N. Devillers, 2013. Assessment of lameness in sows using gait, footprints, postural behavior and foot lesion analysis. Animal, 7: 1163-1173. DOI: 10.1017/S1751731113000098

Karriker, L.A., C.E. Abell, M.D. Pairis, W.A. Holt and G. Sun et al., 2013. Validation of a lameness model in sows using physiological and mechanical measurements. J. Anim. Sci., 91: 130-136. DOI: $10.2527 /$ jas.2011-4994

Loula, T.J., 2000. Increasing sow longevity: The role of people and management. Proceedings of the Allen D. Leman Swine Conference, Aug. 11-11, St. Paul, MN, USA, pp: 139-142.

Lucia, T., G.D. Dial and W.E. Marsh, 2000. Lifetime reproductive and financial performance of female swine. J. Am. Vet. Assoc., 216: 1802-1809.

DOI: $10.2460 /$ javma.2000.216.1802

Main, D.C., J. Clegg, A. Spatz and L.E. Green, 2000. Repeatability of lameness scoring system for finishing pigs. Vet. Rec., 147: 547-576. DOI: $10.1136 / v r .147 .20 .574$

Mohling, C.M., A.K. Johnson, J.F. Coetzee, L.A. Karriker and C.E. Abell et al., 2014. Kinematics as objective tools to evaluate lameness phases in multiparous sows. Livest. Sci., 165: 120-128.

DOI: 10.1016/j/livsci.2014.04.031

O'Callaghan, K.A., P.J. Cripps, D.Y. Downham and R.D. Murray, 2003. Subjective and objective assessment of pain and discomfort due to lameness in dairy cattle. Anim. Welfare, 12: 605-610.
Olsson, A.C., M. Andersson, J. Botermans, D. Rantzer and J. Svensen, 2011. Animal interaction and response to Electronic Sow Feedings (ESF) in 3 different herds and effects of function settings to increase capacity. Livest. Sci., 137: 268-272.

DOI: 10.1016/j.livsci.2010.10.014

Paris-Garcia, M.D., A.K. Johnson, K.J. Stalder, L.A. Karriker and J.F. Coetzee et al., 2014. Measuring the efficacy of flunixin meglumine and meloxicam for lame sows using nociceptive threshold tests. Anim. Welfare, 23: 219-229. DOI: $10.7120 / 09627286.23 .2 .219$

PigCHAMP, 2014. Benchmarking. USA 2014 - year end summary. PigCHAMP Inc., Ames, IA.

Pluym, L.M., D. Maes, J. Vangeyte, K. Mertens and J. Baert et al., 2013. Development of a system for automatic measurements of force and visual stance variables for objective lameness detection in sows: SowSIS. Biosyst. Eng., 116: 64-74.

DOI: 10.1016/j.biosystemseng.2013.06.009

Schenck, E.L., K.A. McMunn, D.S. Rosenstein, R.L. Stroshine and B.D. Nielsen et al., 2008. Exercising stall-housed gilts: Effect on lameness, musculoskeletal system, production and behavior. J. Anim. Sci., 86: 3166-3180. DOI: 10.2527/jas.2008-1046

Stalder, K.J., M. Knauer, T.J. Baas, M.F. Rothschild and J.W. Mabry, 2004. Sow longevity. Pig News Inform., 25: 53N-74N.

Stalder, K.J., C. Lacy, T. Cross and G. Conatser, 2003. Financial impact of average parity of culled females in a breed-to-wean swine operation using replacement gilt net present value analysis. Swine Health Prod., 11: 69-74.

Stock, J.S., J.A. Calderón Díaz, C.E. Abell, T.J. Baas and M.F. Rothschild et al., 2017. Development of an objective feet and leg conformation evaluation method using digital imagery in swine. J. Anim. Sci. Livest. Prod., 1: 2-2.

Sun, G., R.F. Fitzgerald, K.J. Stalder, L.A. Karriker and A.K. Johnson et al., 2011. Development of an embedded microcomputer-based force plate system for measuring sow weight distribution and detection of lameness. Applied Eng. Ag., 27: 475-482. DOI: $10.1186 / 1746-6148-10-37$

Thorup, V.M., F.A. Tøgersen, B. Jørgensen and B.R. Jensen, 2007. Biomechanical gait analysis of pigs walking on solid concrete floor. Animal, 1: 708-715. DOI: $10.1017 / \mathrm{S} 1751731107736753$

Von Wachenfelt, H., S. Pinzke and C. Nilsson, 2009. Force analysis of provoked pig gain on clean and fouled concrete surfaces. Biosyst. Eng., 104: 534-544. DOI: 10.1016/j.biosystemseng.2008.09.002 